\title{
Approaches to the Development of Youth Scientific Tourism in the Siberian Region
}

\author{
Tatiana L. Chernysheva*
}

\author{
Marketing and Service Department, Novosibirsk State Technical University, Novosibirsk, 630073, Russia \\ *Corresponding author. Email: tablack@mail.ru
}

\begin{abstract}
This article describes the relevance of arranging scientific tours for representatives of university student associations engaged in scientific research to laboratories of other universities, where they could learn about this new infrastructure, methods and experimental data of young scientists working on specific topics. Visits to various university research centers and laboratories will increase young people's motivation to engage in science, and, hence, to increase science activities in the region and the country. It is appropriate to begin developing scientific student tourism in the country in the Siberian region, where universities have significant scientific reserves and at the same time much weaker links than universities in the central part of Russia have. This article finds that there is a need to develop a database of scientific and technical developments of leading universities in the Siberian region, which allow us to consider these universities as potential destinations for scientific tourism, as well as to identify problems that impede its development. This validates the proposal to hold a large-scale annual event in Novosibirsk that would distinguish it from other cities and towns and would contribute to the development of youth mobility in the region.
\end{abstract}

Keywords: scientific tourism, university, innovation infrastructure, laboratory facilities, student mobility,

Students Day

\section{TOURISM AS A WAY OF MOTIVATING CREATIVE ACTIVITIES OF UNIVERSITY YOUTH}

The relevance of this study is the need to identify new measures that can join efforts of the scientific community to intensify the development of breakthrough scientific areas in universities of our country. One of such relevant measures would be for revival of contacts between Russian universities, which will lead to an active exchange of experience, as well as development of innovative interdisciplinary projects that can become drivers of Russian science. For the sake of a more intensive development of research at universities, those human resources that are capable of non-standard thinking, new vision of past experience should be used, and these are scientific student associations. Namely young, beginning scientists need to be supported and their efforts need to be concentrated on breakthrough directions [1].

The innovative nature of this applied research, in the course of which the author applied methods of observation, data collection, as well as interviewing students and analyzing university documents, is to justify previously undiscussed methods of motivating creative activity of representatives of scientific student communities by organizing scientific tours to universities in the Siberian region where there are scientific directions, scientific correlated schools, and where studies interesting for beginners are conducted. The first step in the development of scientific tourism in the region is to create a database of scientific developments of Siberian universities, which will become the goals of arrivals for scientific youth.

The purpose of the work is to develop an innovative approach to the development of incentives for achievements of talented students, which can significantly expand the coverage of students with research work starting from the first year. The tasks are to detect problems facing national academic science, to observe the existence of potential resources in the form of representatives of student scientific societies to be developed and maintained in every possible way, and also to identify destinations where scientific tours can be arranged.

\section{RESOURCES OF THE SIBERIAN REGION FOR THE DEVELOPMENT OF YOUTH SCIENTIFIC TOURISM}

\footnotetext{
Siberia has not only rich natural resources, including oil and gas, but also a powerful infrastructure of innovative activities, i.e. research parks, technology transfer centers, laboratory complexes, which are the basis of the modern knowledge economy [2,3]

Siberia takes the third place in Russia in the concentration of science cities located in the Novosibirsk, Tomsk, Krasnoyarsk regions and in the Altai Territory. In particular, Seversk, Zelenogorsk and Zheleznogorsk specialize in nuclear research activities. Of the five Russian academic towns, four are located in Siberia. Novosibirsk
} 
National Research University, National Research Tomsk State University, National Research Tomsk Polytechnic University, Tomsk State University of Control Systems and Radioelectronics, Siberian Federal University are among the best universities in Russia. In order to intensify the linkage of scientific schools working on related topics in different universities in the cities and towns of the Siberian region, to accelerate the implementation of joint projects, and also to strengthen the motivation of students performing promising scientific projects in the university laboratories, it is necessary to develop scientific tourism. The exchange of experimental data, the expansion of scientific and educational links between research centers will lead to improved quality of training of qualified personnel, as well as preservation and activation of scientific potential in the Siberian region. The experience of visiting a university in another Siberian city, getting acquainted with its infrastructure and achievements of its young colleagues in a chosen direction will have a breakthrough effect on further research of young people.

\section{MAIN TYPES OF SCIENTIFIC TOURISM}

As you know, scientific tourism is a type of tourism, which purpose is to participate in various scientific programs without obtaining any material benefits [4].

The tour involves research in a particular territory, which is not a place of permanent residence of a tourist for a period of 24 hours for 6 months at a time. This can be trips to participate in various congresses, symposia and conferences, with the aim of collecting scientific data in the area where the trip takes place. Currently, scientific tourism can be divided into three main types:

1) Study scientific tourism (demonstration of some scientific objects plus expert explanations);

2) Supporting participation, when tourists integrate into scientific works as support staff;

3) Independent research of tourists in collaboration with scientific staff of the host [5].

It seems possible to organize tours that include both simple acquaintance and independent work on the basis of university laboratories in various Siberian cities and towns. We consider the most perfect scientific tourism option when visiting to another university is based on exchange: one team leaves for the university, from where another team arrives at the university of this team.

For example, one team from Tomsk State University comes to Novosibirsk State University, while another team from Novosibirsk State University comes to Tomsk. In our opinion, students will clearly benefit even from a common familiarization with the scientific culture of another university, visits to its laboratories and technology parks, meetings with like-minded young scientists. The environment of another university can have a tremendous impact on the motivation for scientific creative activities, since different, unfamiliar, and first discovered things always contribute to the development. Both the host and the arriving party will get some extra motivation to be proud of the achievements of their own alma mater, as well as a desire and even excitement to work for the benefit of the university. They will make new contacts, new interesting ideas often of an interdisciplinary breakthrough character. It is noteworthy that this kind of students' mobility dates back to the medieval history of universities. When students learned that some university in Europe hosted some big head of science with his lectures, sometimes they made long voyages just to soak up wisdom not yet known [6].

\section{RUSSIAN STUDENTS DAY IN SIBERIAN CITIES}

The development of this kind of tourism requires the initiative of some large Siberian city, which takes the responsibility for search and classification of data on scientific directions presented by universities in the Siberian region, development of an information base of unique university activities and facilities [7], as well as promotion of these facilities through symposia, conferences, scientific battles and publications about them in mass media. Comprehensive science tourism programs, which include not only participation in scientific research, but also represent a complete cultural and entertainment program, should be developed. Together with universities, research institutes, technology parks, business incubators can also welcome young tourists.

Systematic information on possible destinations of youth scientific tourism should be presented as a series of potential motion vectors of a student - traveler on the map of Siberia. Novosibirsk - the largest city in the region, including the number of students, is able to take responsibility for organizing scientific youth tourism in the region. In our opinion, the development of student scientific tourism at universities of the Siberian region will be affected by a large-scale celebration of the Russian Students Day, also known as Tatyana Day. In the mid-19th century, the celebration of students and professors of Moscow University consisted of church services, an official ceremony at the university, and fun student walks around the city. The celebration included museums, libraries, squares, palaces of culture, restaurants - everywhere students and their professors sang "Gaudeamus" and drank mead (honey wine) made by old-time monastery recipes.

Today in Russia there are about 7 million Russian and 3 thousand foreign students, however, unfortunately, Tatyana Day, being an original national holiday, is far from being as popular as in the 19th century. It is celebrated only in metropolitan cities such as Moscow and St. Petersburg, while other cities and towns of Russia do not organize any significant student celebrations in this respect. This is also true for cities and towns of the Siberian region, where such a holiday could popularize universities and raise public interest in their unique achievements in all fields, as well as make student life more saturated, strengthen old and create new student traditions. 
The celebration of the Russian Students Day will make a significant contribution to positioning of Novosibirsk as a young student city, a city of science and new technologies. In total, Novosibirsk has 38 higher educational institutions (13 universities, 9 academies, 16 institutes), in addition, there are 14 branches of universities in other cities of Russia (including Moscow and St. Petersburg). When inviting students and pupils of the region to Novosibirsk, it is appropriate to combine the resources of Novosibirsk universities and offer a program that includes not only an excursion display of the university scientific and sociocultural infrastructure for the comprehensive development of young people, but also active city routes, visiting the snowy town, and organized walking on the central square of the city, as well as a student intellectual competition, a competition of student business ideas, a festival of student amateur activities, KVN (wits and humor competition), an artists' party and evening fireworks. It is appropriate to involve city and region power structures, and, accordingly, their respective sites in the process of organizing this festival.

In conclusion, it should be pointed out that Siberian universities need a clearly formulated policy in the field of development of scientific tourism of student research teams, one of the main objectives of which is to promote existing collective centers, multidisciplinary research laboratories, business incubators. Thus, much more representatives of the country's scientific community will learn about them, business and friendly contacts will be established, new research teams will arise. It is appropriate to start the development of youth scientific tourism in the country with a pilot project in the Siberian region, which has all necessary resources for this, in particular university laboratories, technology parks and business incubators. Scientific tourism will lead to an intensive knowledge interchange, the emergence of interesting interdisciplinary ideas. Students will get acquainted with places of interest of such student towns of the Siberian region as Novosibirsk, Tomsk, Omsk, Krasnoyarsk, Irkutsk, Novokuznetsk, etc. Initiating youth scientific tourism is an unconventional approach to the development of incentives for achievements of talented students, which consists in providing an opportunity for representatives of student scientific teams to get acquainted with scientific research conducted at different universities of the region and, most importantly, to participate in them. This new method of motivating is based on the prospects of organizing scientific tours that can significantly expand the coverage of students with research work starting from the first year. Novosibirsk needs a fullscale annual event that will contribute to positioning of the young student city and developing youth mobility in the region. Such an event could be the annual celebration of Tatyana Day - the Russian Students' Day.

\section{REFERENCES}

[1] V.V. Balashov, A.V. Patsula, R.V. Lenkov, E.A. Gaydukova, The Problem of Motivation of Scientific Activity of University Students, Sociological Research, 2014, V. 4, pp. 127-130

[2] V.V. Kuleshov, G.A. Untura, V.D. Markova V.D., Knowledge economy development: the role of innovative projects in programme of region reindustrialization, Region: economy and sociology, Novosibirsk, 2016, V.3 (91), pp. 28-54.

[3] E.V. Pecheritsa, A.V. Kuchumov, Y.S. Testina, Some of determinants of the sustainability of tourism in Siberian federal district, 17 Theoretical and practical conference Opportunities for development of regional studies of Siberia and neighbouring areas, 2018. DOI: https//doi.org/ 10. 1088/1755-1315/204/1/012056

[4] S. Nunes, V. Sousa, L.M. Grilo, Perfect Resources, Singularities and Scientific Tourism: Methodological Contributions to Valuation and Resources Institutionalization, Proceedings of International Conference of Computational Methods in Sciences and Engineering (ICCMSE 2018). DOI: https: //doi.org/ 10. 1063/1. 5079175

[5] Chernysheva T. L. (2017) Scientific tourism of universities student's associations as way of activization of the country scientific potential, Business. Education. Right, Bulletin of Volgograd business Institute, Volgograd, 2017, no. 1(38), pp. 268-275.

[6] Lukov V.A. (2005) World university culture. Knowledge. Understanding. Ability, Moscow, V.3, pp. 30-38.

[7] P. Rita, N. Rita, C. Oliveira, Data science for hospitality and tourism themes, Worldwide hospitality and tourism themes, 2018, V. 10, Issue 6, pp. 717-725. DOI https: //doi.org/ 10. 1108/WHATT-07-2018-0050 